\title{
MicroRNA-195: a review of its role in cancers
}

This article was published in the following Dove Press journal:

OncoTargets and Therapy

\author{
Wanpeng $\mathrm{Yu}^{\prime}$ \\ Xiao Liang ${ }^{2}$ \\ Xiangdong $\mathrm{Li}^{3}$ \\ Yuan Zhang' \\ Zhenqing Sun ${ }^{4}$ \\ Ying Liu' \\ Jianxun Wang' \\ 'Institute for Translational Medicine, \\ Medical College of Qingdao \\ University, Qingdao 26602I, China \\ ${ }^{2}$ College of Veterinary Medicine, \\ Qingdao Agricultural University, \\ Qingdao 266109, China; ${ }^{3}$ State Key \\ Laboratory of Agrobiotechnology, \\ College of Biological Sciences, \\ China Agricultural University, \\ Beijing I00I93, China; ${ }^{4}$ Department \\ of General Surgery, The Affiliated \\ Hospital of Qingdao University, \\ Qingdao 266003, China
}

Correspondence: Jianxun Wang Institute for Translational Medicine, Medical College of Qingdao University, No 38 Dengzhou Road, Qingdao 26602I, China

Tel +865328299 I79|

Email wangjx@qdu.edu.cn

\begin{abstract}
MicroRNAs (miRNAs) are small and highly conserved noncoding RNAs that regulate gene expression at the posttranscriptional level by binding to the $3^{\prime}$-UTR of target mRNAs. Recently, increasing evidence has highlighted their profound roles in various pathological processes, including human cancers. Deregulated miRNAs function as either oncogenes or tumor suppressor genes in multiple cancer types. Among them, miR-195 has been reported to significantly impact oncogenicity in various neoplasms by binding to critical genes and signaling pathways, enhancing or inhibiting the progression of cancers. In this review, we focus on the expression of miR-195 in regulatory mechanisms and tumor biological processes and discuss the future potential therapeutic implications of diverse types of human malignancies.
\end{abstract}

Keywords: miR-195, cancers, biological processes, biomarker

\section{Introduction}

Cancer is one of the prevalent and deadly diseases threatening human health worldwide. ${ }^{1}$ In recent decades, although great improvements have been achieved in the treatment of cancer, such as surgery, radiochemotherapy and chemotherapy, the 5 -year survival rate for most cancer patients has remained very low due to the lack of efficient early biomarkers. ${ }^{2}$ Therefore, the exploration of new diagnostic biomarkers and potential therapeutic strategies is urgently needed.

MicroRNAs (miRNAs) are tiny, highly conserved, noncoding silencing RNA molecules of $\sim 22$ nucleotides, which regulate gene expression by switching off gene expression or degrading mRNA at the posttranscriptional level. ${ }^{3}$ The first miRNA, lin-4, was identified in 1993, which regulates developmental timing by inhibiting the protein expression of lin-14 via binding the $3^{\prime}$-UTR of its mRNA. ${ }^{4}$ Until now, more than 2,500 known mature miRNAs have been identified in the human genome and recorded in the public miRbase database..$^{5-7}$ More than $\sim 30 \%$ of human protein coding genes are regulated by miRNAs. ${ }^{8,9}$ miRNAs are encoded by the noncoding region of gene, including intergenic or exonic regions or other genes. ${ }^{3,10}$ A single miRNA can effectively influence the expression of several dozen or even hundreds of different mRNAs, and each mRNA can simultaneously be regulated by multiple miRNAs. ${ }^{11,12}$ miRNAs play an unavoidable role in both physiological and pathological processes, such as embryogenesis, metabolism, proliferation, differentiation and apoptosis. ${ }^{13-16}$

Emerging data have revealed that miRNAs can target many of the programs that are tightly related to almost all aspects of cancer biopathological features, suggesting that miRNAs can play crucial roles in the pathogenesis of cancer, including initiation, promotion, malignant conversion, progression and metastasis of the oncogenic state. ${ }^{17,18}$ Based on the miRNA expression and its validated targets, miRNAs might function as oncogenes (oncomiRs) or tumor suppressors in cancer. ${ }^{19}$ Therefore, miRNAs are considered as diagnostic, prognostic and therapeutic biomarkers in almost all cancers. 


\section{miR-I 95}

miR-195 is one of the miR-15/107 family members, which are stress inducible and activated in multiple diseases, such as cancers, heart failure and schizophrenia. Members of the miR-15/107 group have a similar sequence, AGCAGC, near the $5^{\prime}$ end of the mature miRNA, named AGCx 2 miRNA. ${ }^{20}$ The human miR-195 gene originates from intron 7, which is located on chromosome $17 \mathrm{p} 13.1$ and on the reverse strand of the mRNA gene AK098506, encoding an unknown functional protein. ${ }^{21,22}$ The predicted stem-loop structure of miR195 determined using the miRBase (http://mirbase.org/) is shown in Figure 1A. The miR-195 hairpin gives rise to the "guide strand" miR-195-5p and the sister "passenger" strand miR-195-3p (Figure 1B). Dysregulation of miR-195 may contribute to the pathogenesis of multiple diseases. For example, miR-195 has been reported to be related to Alzheimer's disease (AD), regulating important brain growth factors related to schizophrenia. ${ }^{23}$ In addition, miR-195 has been found to be upregulated during cardiac hypertrophy, and cardiac overexpression of miR-195 results in pathological cardiac growth and heart failure in transgenic mice. ${ }^{24}$ In particular, miR-195 exerts its function by targeting the mRNAs of multiple proteins as oncogenes or tumor suppressors in several cancers, including breast cancer, ${ }^{25}$ lung cancer, ${ }^{26}$ prostate cancer $(\mathrm{PCa}),{ }^{26}$ gastric cancer (GC), ${ }^{27}$ colorectal cancer (CRC), ${ }^{28}$ hepatocellular cancer (HCC) and bladder cancer (BC). ${ }^{29}$ In this review, we discuss the current knowledge about the effects and mechanisms of miR-195 in diverse types of malignancies (Table 1).

\section{miR- 195 in various cancers miR- 195 and digestive system cancer $\mathrm{HCC}$}

HCC, ranked as the second leading cause of cancer mortality in human beings, is one of the most prevalent malignancies worldwide. ${ }^{30} \mathrm{HCC}$ is difficult to diagnose at an early stage due to a lack of understanding of HCC formation and progression. Therefore, identifying novel tumor-suppressive molecules for HCC is urgently needed.

$\mathrm{Xu}$ et $\mathrm{al}^{31}$ discovered that miR-195 suppresses HCC to form colonies in vitro and to develop tumors in mice. The $\mathrm{Rb}-\mathrm{E} 2 \mathrm{~F}$ signaling axis acts as a key checkpoint in cell cycle progression. In addition, miR-195 blocks the G1/S transition by repressing $\mathrm{Rb}-\mathrm{E} 2 \mathrm{~F}$ signaling through regulating the expression of target genes, such as CCND1, CDK6 and E2F3. In addition, Yang et $\mathrm{al}^{32}$ confirmed that miR-195 upregulation can promote apoptosis of HCC cells by increasing the expression of large tumor suppressor kinase 2 (LATS2) and P53 while decreasing $C D K 2$ expression. LATS2, considered as a tumor suppressor gene, has been believed to cause cell cycle arrest via inhibition of $C D K 2$ activity. ${ }^{33}$ Numerous studies have confirmed the essential roles of NF- $\mathrm{KB}$ as a link between inflammation and cancer. ${ }^{34}$ Ding et $\mathrm{al}^{35}$ corroborated that miR-195 suppresses HCC development via the downexpression of multiple NF- $\kappa \mathrm{B}$ downstream effectors by directly targeting $I K K \alpha$ and TAB3. In addition, the suppression of HCC angiogenesis and metastasis by miR-195 was affirmed by Wang et al, ${ }^{36}$ partly via targeting the proangiogenic factor $V E G F$ and prometastatic factors $V A V 2$ and cell division control protein 42 homolog (CDC42). Protein-L-isoaspartate (D-aspartate) $O$-methyltransferase 1 (PCMT1), a member of the type II class of protein carboxyl methyltransferase enzymes, has been verified to be involved in increasing the cancer cell life span. PCMT1 has been found to be negatively regulated in HCC by miR-195, which targets putative binding sites in its $3^{\prime}$-UTR. ${ }^{37}$ Yang et al $^{38}$ presumed that miR-195 overexpression is important to regulate cell proliferation, cell cycle and apoptosis by targeting $W N T 3 A$ in HCC. $W N T 3 A$, a member of the Wnt family, has been reported to serve as a key therapeutic

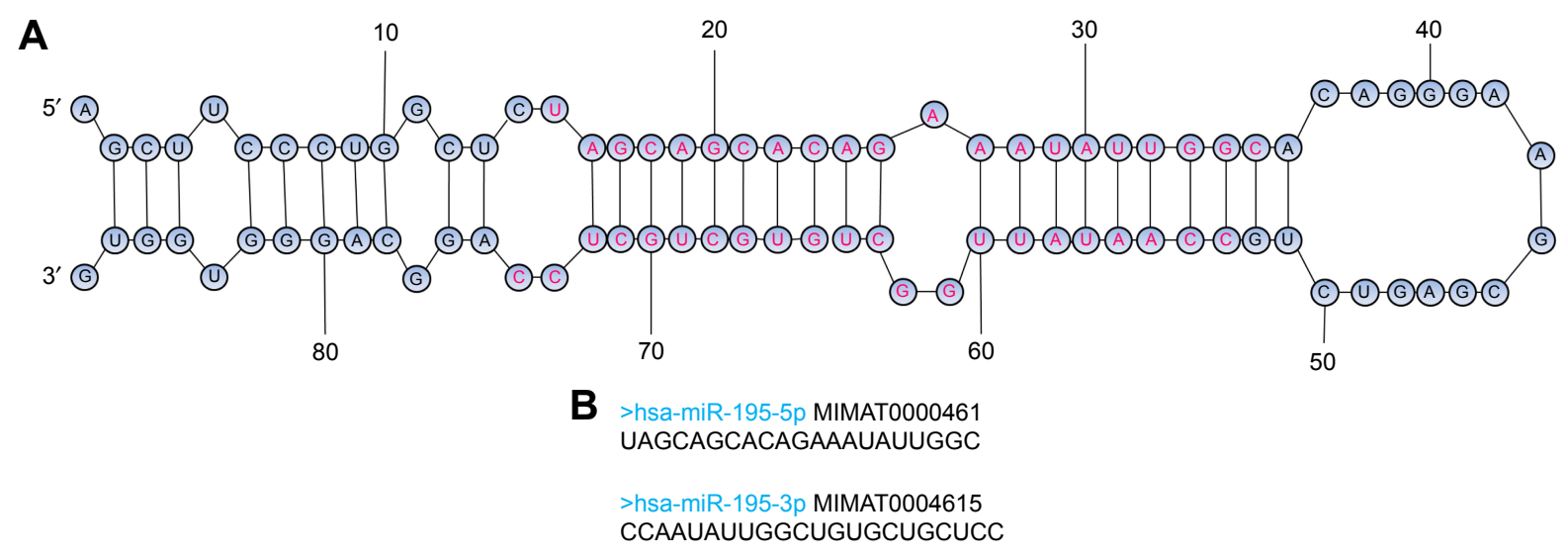

Figure I The structure and sequence of miR-195.

Notes: (A) Stem-loop structure of miR-195. (B) Mature sequence of miR-195. Two different mature miR-195 sequences, namely miR-195-5p and miR-195-3p. 
Table I miR-195 alterations in cancers

\begin{tabular}{|c|c|c|c|c|c|}
\hline Cancer type & & Regulated expression & Target gene & Related functions & References \\
\hline \multirow[t]{4}{*}{$\begin{array}{l}\text { Digestive } \\
\text { system cancer }\end{array}$} & $\mathrm{HCC}$ & Downregulated & $\begin{array}{l}\text { CCNDI, CDK6, E2F3, Lats2, } \\
\text { IKK } \alpha, \text { TAB3, VEGF, PCMTI, } \\
\text { WNT3A, SRC-3, CBX4, } \\
\text { PHFI9, FGF2, VEGFA, YAP, } \\
\text { CDC42, VAV2 }\end{array}$ & $\begin{array}{l}\text { Cell cycle, proliferation, } \\
\text { migration, angiogenesis, } \\
\text { metastasis, apoptosis, invasion }\end{array}$ & $3 \mathrm{I}, 32,35-38,4 \mathrm{I}-45$ \\
\hline & CRC & Downregulated & $\begin{array}{l}\text { BCL-2, CARMA3, YAP, CDK2, } \\
\text { CDK8, FGF2, IGF2BP2, RAFI, } \\
\text { CARMI, BCL2L2, WEEI, } \\
\text { CHKI }\end{array}$ & $\begin{array}{l}\text { Apoptosis, viability, metastasis, } \\
\text { proliferation, metastasis, } \\
\text { migration, EMT, radioresistance, } \\
\text { chemotherapy resistant }\end{array}$ & $\begin{array}{l}52-54,56,58,61,64 \\
67,68\end{array}$ \\
\hline & GC & Downregulated & CDK6, AKT3, bFGF & $\begin{array}{l}\text { Cell cycle, proliferation, } \\
\text { migration, migration, invasion, } \\
\text { chemotherapy resistant }\end{array}$ & $27,73,75$ \\
\hline & EC & Downregulated & $C D C 42$ & Proliferation, invasion & 81 \\
\hline \multirow{3}{*}{$\begin{array}{l}\text { Respiratory } \\
\text { system cancer } \\
\text { Urinary } \\
\text { system cancer }\end{array}$} & Lung cancer & Downregulated & MYB, IGFIR, HDGF, CHKI & $\begin{array}{l}\text { Proliferation, migration, } \\
\text { invasion, radiosensitivity }\end{array}$ & $85,86,88,89$ \\
\hline & BC & Downregulated & $\begin{array}{l}\text { CDK4, GLUT3, BIRC5, } \\
\text { WNT7A, CDC42, ARL2 }\end{array}$ & $\begin{array}{l}\text { Cell cycle, proliferation, } \\
\text { apoptosis, migration, invasion, } \\
\text { viability }\end{array}$ & $29,96,97,101,103$ \\
\hline & Kidney cancer & Downregulated & VEGFR2 & $\begin{array}{l}\text { Proliferation, migration, } \\
\text { invasion, metastasis }\end{array}$ & 108 \\
\hline \multirow{3}{*}{$\begin{array}{l}\text { Bone cancer } \\
\text { Brain cancer }\end{array}$} & OS cancer & Downregulated & FASN, CCNDI, NKDI & Migration, invasion, metastasis & $124,127,128$ \\
\hline & Glioma & Downregulated & $\begin{array}{l}\text { E2F3, CCND3, CCNDI, } \\
\text { CCNEI }\end{array}$ & Proliferation, invasion & 133,134 \\
\hline & & Upregulated & Unknown & Chemotherapy resistant & 136 \\
\hline \multirow{4}{*}{$\begin{array}{l}\text { Head and } \\
\text { neck cancer }\end{array}$} & TSCC & Downregulated & CCNDI, BCL-2 & Proliferation, apoptosis & 138 \\
\hline & HNSCC & Upregulated & Unknown & Prognosis biomarker & 140 \\
\hline & LSCC & Downregulated & DCUNIDI, BCL-2 & Growth, invasion, apoptosis & 142,143 \\
\hline & OSCC & Downregulated & TRIMI4, CDK6 & Proliferation, invasion, migration & 145,146 \\
\hline \multirow[t]{2}{*}{ Skin cancer } & Melanoma & Downregulated & $\mathrm{PHBI}$ & Proliferation & 150 \\
\hline & & Upregulated & WEEI & Migration, invasion & 148 \\
\hline \multirow[t]{4}{*}{$\begin{array}{l}\text { Endocrine } \\
\text { cancer }\end{array}$} & $\mathrm{ACC}$ & Downregulated & & $\begin{array}{l}\text { Predictive biomarker for patient } \\
\text { survival }\end{array}$ & 174 \\
\hline & $\begin{array}{l}\text { Thyroid } \\
\text { cancer }\end{array}$ & Downregulated & RAFI, CCNDI, FGF2 & Proliferation, migration, invasion & 176,177 \\
\hline & & Downregulated & DCLKI & Proliferation, migration, invasion & 179 \\
\hline & Breast cancer & Downregulated & $\begin{array}{l}\text { CCNEI, ACACA, FASN, } \\
\text { HMGCR, CYP27BI, RAFI, } \\
\text { WNT3A, IRSI }\end{array}$ & $\begin{array}{l}\text { Cell cycle, EMT, angiogenesis, } \\
\text { invasion, chemotherapy } \\
\text { resistant }\end{array}$ & $\begin{array}{l}25,154,162,163,166, \\
168\end{array}$ \\
\hline \multirow[t]{2}{*}{$\begin{array}{l}\text { Reproductive } \\
\text { system cancer }\end{array}$} & $\mathrm{CC}$ & Downregulated & $\begin{array}{l}\text { HDGF, CCNDI, CCND2, } \\
\text { MYB, SMAD3 }\end{array}$ & Proliferation, migration, invasion & $111-115$ \\
\hline & $\mathrm{PCa}$ & Downregulated & $\begin{array}{l}\text { BCOXI, FGF2, FRA-I, } \\
\text { RPS6KBI, PRRII }\end{array}$ & $\begin{array}{l}\text { Proliferation, metastasis, EMT, } \\
\text { angiogenesis, migration }\end{array}$ & $|17-12|$ \\
\hline
\end{tabular}

Abbreviations: ACC, adrenocortical cancer; BC, bladder cancer; CC, cervical cancer; CRC, colorectal cancer; EC, esophageal cancer; EMT, epithelial-mesenchymal transition; GC, gastric cancer; HCC, hepatocellular cancer; HNSCC, head and neck squamous cell cancer; LSCC, laryngeal squamous cell carcinoma; OS, osteosarcoma; OSCC, oral squamous cell carcinoma; PC, pancreatic cancer; PCa, prostate cancer; TSCC, tongue squamous cell carcinoma.

target in tumorigenesis. ${ }^{39}$ The steroid receptor coactivator-3 $(S R C-3)$ is frequently amplified and overexpressed in multiple human cancers. ${ }^{40}$ However, its molecular mechanism remains largely unexplored in HCC. The underlying mechanism of the miR-195 anti-proliferation activity in HCC occurs through the suppression of SRC-3. ${ }^{41}$ Furthermore, based on two other studies in 2015, miR-195 showed antiproliferative, anti-invasive and anti-migratory characteristics by inhibiting chromobox homolog 4 (CBX4) and PHD finger protein 19 (PHF19) gene expression in HCC. ${ }^{42,43}$ The lung is the most frequent metastatic organ site of HCC. Wang et $\mathrm{al}^{44}$ found that the expression of miR-195 is significantly downregulated in lung metastatic cell lines. Furthermore, they claimed that miR-195 functions as a vital suppressive regulator in lung metastasis of HCC by targeting angiogenesis-related gene fibroblast growth factor $2(F G F 2)$ and vascular endothelial growth factor A $(V E G F A)$. Recently, Yu et al ${ }^{45}$ demonstrated that miR-195 inhibits epithelial-mesenchymal transition (EMT) in HCC by suppressing YAP.

In another study, lncRNA small mucleolar RNA host gene 1 (SNHG1) was identified as a potential sponge of miR-195. ${ }^{46}$ The function and clinical analysis of SNHG1 
showed that it enhances HCC tissues and cell lines compared with normal tissues and cell lines. Downregulation of SNHG1 represses the proliferation and invasion of HCC cells and promotes the expression of miR-195. Furthermore, miR-195 has been reported to enhance the susceptibility of HCC cells to 5-fluorouracil (5-FU), at least in part by inhibiting the expression of Bcl-w. ${ }^{47}$

Moreover, miR-195 has been recognized as a circulating miRNA, and its serum levels have been shown to be a diagnostic marker. The analysis of circulating exosomes isolated from HCC patients, together with chronic hepatitis (CHB) and liver cirrhosis (LC) patients, has also revealed the presence of miR-195 (downregulation in HCC), supporting serum exosomal miR-195 as a novel serological biomarker for HCC. ${ }^{48}$ These studies indicate that miR-195 may participate in the pathogenesis of $\mathrm{HCC}$ and contribute to the diagnosis and prognosis of this disease.

\section{CRC}

$\mathrm{CRC}$ is the third most commonly diagnosed cancer and the third leading cause of cancer-related death in the USA, with more than 1 million people diagnosed annually. ${ }^{49}$ Despite improvements in clinical diagnosis and treatment technology for CRC treatment, the 5-year survival rate of CRC is low due to a lack of effective interventions and specific diagnostic markers for early diagnosis. ${ }^{50}$ Thus, it is essential to find novel therapy targets and valuable biomarkers for CRC.

Liu et $\mathrm{al}^{51}$ found that miR-195 is markedly decreased in surgically removed CRC tissues and cell lines compared with adjacent non-tumor tissues and normal cells. There is evidence that the upregulation of miR-195 can inhibit CRC cell proliferation via the downregulation of $C D K 2$ and $C D K 8^{52,53}$ and further promote CRC cell apoptosis and reduce cell viability by repressing expression of the antiapoptotic protein BCL-2. ${ }^{54}$ Another study showed that miR-195 is significantly reduced in CRC patients with lymph node metastasis and an advanced tumor stage. ${ }^{55}$ Furthermore, Wang et al ${ }^{56}$ showed that miR-195 suppresses CRC cell proliferation and invasion in vitro by downregulating caspase recruitment domain and membrane-associated guanylate kinase-like domain protein 3 (CARMA3), which has been believed to play a vital role in tumorigenesis. ${ }^{57}$ Signaling pathways, such as Hippo/YAP, also play crucial roles in CRC progression, ${ }^{58}$ similar to the role of miR-195 described in HCC. ${ }^{45}$ Previous studies have revealed that $F G F 2$ plays a significant role in cell growth, differentiation and function in $\mathrm{CRC}$, and Wnt signaling was identified as a key pathway in tumor development and progression. ${ }^{59,60}$ Zhang et al ${ }^{52}$ reported that miR-195 exerts antiproliferative functions by targeting $F G F 2$ and blocking the Wnt/ $\beta$-catenin pathway. Recently, insulin-like growth factor (IGF2) mRNA-binding protein 2 (IGF2BP2) was identified as a posttranscriptional regulatory mRNA-binding factor that contributes to $\mathrm{CRC}$ carcinogenesis. ${ }^{61} R A F 1$, also known as cRaf, is a member of the MAPK pathway and can be bound by miR-195 at its 3'-UTR. ${ }^{25,62}$ However, the expression of miR-195 is negatively correlated with IGF2BP2 and $R A F 1$, and $I G F 2 B P 2$ regulates $R A F-1$ mRNA stability by affecting miR-195 synthesis in CRC. ${ }^{61}$

Furthermore, miRNA can serve as a target for the development of novel miRNA-based therapeutic strategies to overcome radioresistance. ${ }^{63} \mathrm{~A}$ very recent study showed that miR-195 sensitizes CRC cells to radiation through the regulation of genes involved in cell proliferation and survival, such as coactivator-associated arginine methyltransferase 1 (CARM1). ${ }^{64} C A R M 1$, also known as PRMT4, can exert both oncogenic and tumor-suppressive functions. ${ }^{65,66}$ Recent studies have also reported that miR195 is significantly associated with the regulation of drug resistance. For example, miR-195 has been demonstrated to sensitize the CRC lines, HT29 and LOVE, to doxorubicin by directly targeting $B C L 2 L 2$, which is described as an important antiapoptotic regulator by suppressing the deathpromoting activity. ${ }^{67}$

Nevertheless, a puzzling result was reported by Kim et al, ${ }^{68}$ in which miR-195 desensitized human CRC HCT-116 cells to 5-FU through direct inhibition of the expression of the G2 checkpoint kinase WEE1 and checkpoint kinase (CHK1). Although it is difficult to determine why miR-195 has opposite functions in the regulation of drug sensitivity in CRC, we inferred that the role of miR-195 might be affected by the disease stage and cell type-specific environment. In addition, miR-195 expression levels might be used as a predictive factor for early detection and screening of CRC in the meta-study by Li et al. ${ }^{69}$ Thus, miR-195 may be a novel marker reflecting the development of CRC.

\section{GC}

GC, which develops from the lining of the stomach, is one of the most lethal malignancies of the digestive system. ${ }^{70}$ The 5 -year survival rate of GC patients is unsatisfactory due to its recurrence and metastasis. ${ }^{71}$ The majority of GC patients are diagnosed at an advanced stage given the lack of appropriate biomarkers and specific early symptoms. Therefore, it is urgent to discover novel and suitable prognostic biomarkers 
of GC. Until now, dysregulation of miRNA expression is considered to play a crucial role in GC development. ${ }^{72}$

In the study by Deng et al, ${ }^{27}$ miR-195 was found to be abnormally expressed and epigenetically regulated in GC cell lines and tissues via the suppression of CDK6 and VEGF signaling. In addition, miR-195 played a critical role in suppressing tumor progression in human GC in vitro and in vivo, probably exerting its role by modulating its target gene $A K T 3 .{ }^{73}$ AKT3 is a member of the AKT subfamily of serine/threonine protein in the PI3K/AKT signaling pathway, which plays a significant role in many human cancers including GC. ${ }^{74}$ Moreover, miR-195 has a significant effect on the chemotherapy sensitivity of cisplatin and clinical prognosis. ${ }^{73}$ Another investigation revealed that, by interacting with $b F G F$ 3'-UTR, overexpression of miR-195 could decrease $b F G F$ expression and repress cellular migration and invasion of the GC cell lines, SNU-1 and KATO-3, as well as tumor formation in a xenograft mouse model. ${ }^{75} \mathrm{bFGF}$ is a pro-tumor factor that is involved in cancer angiogenesis, metastasis and tumor infiltration. ${ }^{76}$

Emerging studies have examined the prognostic role of miR-195 in GC. The levels of miR-195 are highly decreased in patient-derived GC tissue and plasma of GC patients compared with paracancerous tissue and plasma in the healthy control group. In addition, decreased miR-195 is negatively associated with distant lymph node metastasis, an advanced clinical stage and infiltration in GC patients. ${ }^{77}$ Overall, these data suggest that miR-195 could be used as a diagnostic and prognostic marker of GC.

\section{Esophageal cancer (EC)}

$\mathrm{EC}$, as a major global heath challenge, is the eighth most common malignancy and sixth leading cause of cancer-related death worldwide. ${ }^{70}$ There are two major subtypes of EC in terms of distinct etiology and epidemiology: esophageal squamous cell carcinoma and esophageal adenocarcinoma (OAC). Oral squamous cell carcinoma (OSCC) is the predominant histological type of EC, accounting for more than $90 \%$ of all EC cases globally. ${ }^{78}$ Despite extensive studies and significant improvements in diagnosis and treatment, the overall 5-year survival is still dismal at $<10 \%-15 \% .{ }^{79}$ Thus, it is imperative to discover molecular biomarkers for early tumor detection and novel effective therapeutic methods.

Several published papers suggest miR-195 as a tumor suppressor in OSCC. First, by using a microarray assay, miR-195 was found to have decreased expression in OSCC compared with paired non-OSCC tissue. ${ }^{80}$ Another study demonstrated that miR-195 reduces the proliferation and invasion of OSCC cells. The researchers argue that the antiproliferative and anti-invasion effects of miR-195 can be attributed to its suppression of $C D C 42 .{ }^{81} C D C 42$, a Rho family GTPase, is involved in the regulation of the cell cycle and has been shown to be overexpressed in various human cancers. ${ }^{82}$ Furthermore, Sun et al ${ }^{83}$ observed that combined expression of miR-195/CDC42 is a more efficacious prognostic marker for progression-free survival and overall survival of OSCC patients than miR-195 or CDC42 alone. These studies lay the foundation for further analysis of miR-195 as a novel therapy for EC.

\section{miR-I95 and the respiratory system cancer}

\section{Lung cancer}

Lung cancer is the number one cause of cancer mortality in both sexes worldwide. Non-small-cell lung cancer (NSCLC) is a major class of lung cancer, accounting for nearly $80 \%$ of all lung cancer cases. ${ }^{84}$ Thus, a better understanding of the mechanism underlying NSCLC progression is urgently needed.

miR-195 has been shown to serve as a tumor suppressor by inhibiting NSCLC cell proliferation, migration and invasion via targeting $M Y B{ }^{85}$ In addition, miR-195 has been found to diminish NSCLC cell proliferation and metastasis, partly by targeting insulin-like growth factor 1 receptor $(I G F 1 R),{ }^{86}$ which plays a positive role in tumorigenesis. ${ }^{87}$ Another two studies have expanded the suppressive role of miR-195 in NSCLC. Guo et $\mathrm{al}^{88}$ suggested that miR-195 is a tumor suppressor in NSCLC by targeting hepatoma-derived growth factor $(H D G F)$, which is expressed in many cancers. In addition, checkpoint kinase 1 ( $\mathrm{CHK} 1)$, a potential target for cancer therapy, is downregulated by miR-195 according to Liu et al. ${ }^{89}$

Furthermore, Wu et $\mathrm{al}^{90}$ showed that an oncogenic LncRNA (PVT1) regulates the effect of NSCLC cells on radiosensitivity by sponging $\mathrm{miR}-195$ and that these effects can be reversed by miR-195 overexpression. Therefore, miR-195 might be used as a promising biomarker for the diagnosis and as a potential target for the treatment of NSCLC in the future.

\section{miR-195 and urinary system cancer $B C$}

$\mathrm{BC}$ is believed to be one of the most prevalent genitourinary tract malignancies in both sexes worldwide. ${ }^{91}$ Approximately 
386,000 new cases of BC patients and 150,000 deaths occur globally each year. ${ }^{92}$ Many factors contribute to the carcinogenesis of $\mathrm{BC}$, such as genetic and epigenetic alterations, especially the downregulation of tumor suppressors. ${ }^{93}$ However, the molecular mechanisms of bladder tumorigenesis remain unclear. Therefore, it is necessary to elucidate new detailed mechanisms and to identify effective diagnostic biomarkers in $\mathrm{BC}$.

Canturk et $\mathrm{al}^{94}$ aimed to construct miRNA regulatory networks of BC-related miRNAs and their target genes using microarray and Kyoto Encyclopedia of Genes and Genomes enrichment analysis. The results of their study revealed reduced expression of hsa-miR-195-5p in human $\mathrm{BC}$ compared with normal bladder urothelium. Moreover, they showed that hsa-miR-195-5p, hsa-let-7c and hsa-miR125b-5p hub miRNAs along with CDK6, CDK4 and ERBB3 hub genes might exist in the same BC pathway. Perturbation of CDK4, the key regulator of the G1/S transition, together with cyclin D1 is linked to cancer and tumorigenesis. ${ }^{95}$ In another paper, $C D K 4$ has also been verified as a direct target of miR-195, which exerts a growth-suppressing function in the BC cell line, T24. ${ }^{96}$ Another report has demonstrated that miR-195 decreases T24 glucose uptake and inhibits cell proliferation while inducing cell apoptosis by negatively regulating GLUT member 3 (GLUT3). ${ }^{97}$ GLUT3 is a member of GLUTs, which has greater transport capacity and a higher affinity for glucose to support tumorigenesis compared with other GLUT members. ${ }^{98}$ By using deep sequencing technology, Itesako et $\mathrm{al}^{29}$ confirmed that the downregulation of the miR-195/497 cluster contributed to BC progression and metastasis. Transfection of mature miR-195 or miR-497 into two BC cell lines (BOY and T24) significantly inhibited cancer cell proliferation, migration and invasion, suggesting that the miR-195/497 cluster functioned as a tumor suppressor in BC by directly targeting BIRC5 and WNT7A.$^{29}$ BIRC5 is a member of the inhibitor of apoptosis (IAP) family regarded as an oncogene and reported as a diagnostic biomarker for BC. ${ }^{99,100}$ In addition, Zhao et al $^{101}$ found that miR-195 could significantly inhibit the proliferation of BC cells in vitro, partially via the inhibition of Cdc42/STAT3 signaling.

Urothelial cancer-associated 1 (UCA1) is an lncRNA that is highly expressed in $\mathrm{BC}$ tissues and has been reported to play oncogenic roles in $\mathrm{BC}$ progression. ${ }^{102} \mathrm{~A}$ recent paper indicated that UCA1 enhances mitochondrial function and BC cell viability by functioning as an important ceRNA for miR-195 to regulate its target gene ADP-ribosylation factor-like GTPase 2 (ARL2) in vivo and in vitro. ${ }^{103} A R L 2$ is an activator of $\mathrm{ATP} / \mathrm{ADP}$ transporters belonging to the ADP-ribosylation factor family, ${ }^{104}$ functions in both cytosol and mitochondrial and is located in the inner membrane space of mitochondria. ${ }^{105}$ Elucidation of UCA1/miR-195/ARL2 signaling network provides important clues for understanding the molecular pathology of BC. Collectively, these studies indicate that miR-195 could be used as a potentially valuable biomarker for $\mathrm{BC}$ diagnosis and therapy.

\section{Kidney cancer}

Renal cell carcinoma (RCC) is one of the most malignant diagnostic urological cancers of the adult kidney. RCC accounts for approximately $3 \%$ of cancers and resulted in an estimated 13,860 deaths in the USA in 2014. ${ }^{106}$ Clear cell RCC (ccRCC) is the main histological category of RCC, accounting for $75 \%$ of cases. ${ }^{107}$ Based on Sun et al, ${ }^{108}$ the expression levels of miR-195 in ccRCC samples were significantly reduced compared with the control groups. Moreover, the overexpression of miR-195 could suppress the proliferation, migration, invasion and apoptosis of a human ccRCC cell line (ACHN) through inhibiting both the Raf/MEK/ERK and the PI3K/AKT signaling pathways by targeting VEGFR2. In addition, Wang et al ${ }^{109}$ showed that miR-195-5p together with miR-29a-3p/29 c-3p participates in androgen receptor (AR)-enhanced ccRCC cell metastasis, which indirectly confirmed that miR-195 functions as a suppressor in RCC. Overall, these findings help to define miR-195 as a tumor suppressor in RCC, yet more work is needed to elucidate its use as a potential therapeutic approach for RCC.

\section{miR-I95 and reproductive system cancer Cervical cancer (CC)}

Among women worldwide, $\mathrm{CC}$ is one of the most prevalent gynecological malignancies, ranked as the fourth leading cause of cancer-associated mortality. ${ }^{70}$ However, the mechanisms underlying the oncology of $\mathrm{CC}$ are still largely unknown. Therefore, novel biomarkers and effective therapeutic targets for early detection and treatment of $\mathrm{CC}$ are urgently needed.

The miR-195 level in serum can be used for the diagnosis of CC. Zhang et $\mathrm{al}^{110}$ conducted a study of miRNA markers in CC patients' serum and found that the levels of four miRNAs (miR-195, miR-16-2*, miR-2861 and miR-497) were differentially expressed in the serum of $\mathrm{CC}$ patients compared with normal controls and considered them as novel noninvasive biomarkers for the detection of CC. Song et al ${ }^{111}$ 
analyzed the behavior of CC tumors by MTT using a dual luciferase reporter assay and showed that the overexpression of miR-195 inhibited cell proliferation, migration and invasion by suppression of $H D G F$. The anti-tumorigenic role of miR-195 in CC was not solely due to $H D G F$, as miR-195 also targets CCND1, CCND2, MYB and SMAD3 in CC. ${ }^{112-115}$ $S M A D 3$, a member of the SMAD family, is related to tumor growth in cancer progression. ${ }^{116}$ In general, miR-195 shows advantageous characteristics as a novel biomarker for early diagnosis and as a therapeutic target in $\mathrm{CC}$.

\section{$\mathrm{PCa}$}

$\mathrm{PCa}$ is the most commonly diagnosed cancer in the male population worldwide and accounted for approximately 30,000 American deaths in 2014. ${ }^{106}$ The dramatic decrease in the survival rate in late-stage PCa is largely attributed to metastasis, highlighting the need to develop therapeutic options for advanced PCa. Studies investigating PCa have revealed that miR-195 acts as a tumor suppressor, and mechanistically, researchers have identified several miR-195 targets in PCa. Concretely, miR-195 can regulate the invasiveness of PCa cells and metastasis of PCa xenografts by regulating breast cancer-overexpressed gene 1 (BCOX1). ${ }^{117}$ In addition, Liu et $\mathrm{l}^{118}$ demonstrated that miR-195 specifically inhibits the EMT process of PCa cells through its target gene FGF2. In addition, in PCa cell lines, miR-195 shows an inhibitory effect on cell migratory ability by targeting Fra-1, which is overexpressed in several tumors. ${ }^{119}$ In addition, miR-195 can be implicated into the progression of $\mathrm{PCa}$ by regulating ribosomal protein S6 kinase B1 (RPS6KB1) signaling, and thus the miR-195-RPS6KB1 axis represents a novel potential therapeutic target for PCa treatment. ${ }^{120}$ A follow-up study from this group in 2018 claimed that miR-195 could directly inhibit the expression of proline rich 11 (PRR11) and that the upregulation of miR-195 or knockdown PRR11 could suppress PCa angiogenesis and proliferation in vivo and in vitro. ${ }^{121}$ Overall, miR-195 could serve as a biomarker and therapeutic target in PCa.

\section{miR- 195 and bone cancer Osteosarcoma (OS)}

OS is a prevalent primary malignant bone cancer with high morbidity and mortality in youths, the incidence of which is approximately 4 million per year worldwide. ${ }^{122}$ Due to the high metastasis and recurrence potential, it is of great importance to explore new targets for the treatment of OS metastasis. The circulating miRNAs present in the serum and plasma of OS patients are valuable for the early detection and prognosis prediction of OS. For example, a low level of circulating miR-195-5p and miR-199a-3p levels in plasma was significantly associated with metastasis among patients with OS. ${ }^{123}$ In OS, miR-195 was observed to suppress tumorigenicity by targeting multiple pro-survival genes. In the OS cell line, U2OS, restoration of miR-195 markedly inhibited cell invasion and migration by directly targeting fatty acid synthase $(F A S N) .{ }^{124} \mathrm{FASN}$, an enzyme that is crucial in endogenous lipogenesis, plays a key role in cancer cell metastasis. ${ }^{125,126}$ In addition, miR-195 also targets CCND1 and naked cuticle homolog 1 (NKD1) in independent studies, thus inhibiting OS cell proliferation and metastasis in vivo and in vitro. ${ }^{127,128}$ As one negative regulator of Wnt signaling pathway, $N K D 1$ is overexpressed in certain types of cancer. ${ }^{129,130}$ Overall, these findings indicate the crucial role of miR-195 in OS and the potential ability of miR-195 to serve as a promising prognostic factor for OS.

\section{miR-195 and brain cancer Glioma}

Glioma is the most lethal primary malignant brain neoplasm, leading to significant mortality worldwide annually. ${ }^{131}$ Some research papers have reported that miR-195 has the ability to diminish the progression of glioma. Lakomy et $\mathrm{al}^{132}$ demonstrated a significant downregulation of miR-195 in glioblastoma multiforme samples compared with control nonmalignant brain tissues. Based on the study by Zhang et al, ${ }^{133} \mathrm{miR}-195$ plays a role in impairing glioblastoma cell proliferation and invasion by targeting E2F3 and CCND3. Furthermore, Hui et al reported that miR-195 can inhibit the proliferation of human glioma cells by directly targeting CCND1 and CCNE1. ${ }^{134}$

In stark contrast to the abovementioned studies, there is evidence that miR-195 is an oncogenic miRNA in glioma. Ujifuku et $\mathrm{al}^{135}$ concluded that miR-195 along with miR455-3p and miR-10a* are upregulated in glioblastoma multiforme, inducing enhanced temozolomide resistance, yet the knockdown of miR-195 can reverse temozolomide resistance. In a separate study, miR-195 showed a sevenfold decrease in the expression of cyclosporin $\mathrm{A}$ (CsA)-treated U-87 MG glioma cells, suggesting that miR195 might act as an oncogene in glioma. ${ }^{136}$ These studies revealed that miR-195 overexpression might assist with the spread of glioma, while others have demonstrated its suppressive effects. 


\section{miR-I95 and head and neck cancer}

Head and neck cancer, which ranks fifth among all carcinomas, is a group of cancers that start within the mouth, larynx, nose, throat, sinuses or salivary glands with an incidence of 500,000 new cases annually. ${ }^{137}$ Cumulative data clearly suggest that miR-195 should be explored as a prognostic marker for various types of head and neck cancers. Jia et a ${ }^{138}$ demonstrated a decrease in miR-195 expression in tongue squamous cell carcinoma (TSCC) compared with adjacent nonmalignant tissues and provided evidence that miR-195 may be a prognostic factor for TSCC patients. Moreover, the antitumor effects of miR-195 in TSCC may be partially mediated by its inhibition of $C C N D 1$ and $B C L-2$ expression. ${ }^{138}$ Based on the study by Santos et al, ${ }^{139}$ miR-195, miR-17, miR-132 and miR-221 seem to play crucial roles as tumor suppressors in salivary function. However, Summerer et $\mathrm{al}^{140}$ reported opposite data in a study of differential plasma miRNA expression between head and neck squamous cell cancer (HNSCC) patients and healthy individuals. They observed that high plasma expression of miR-195-5p in a panel of four miRNAs (miR-142-3p, miR-185-5p, miR-574-3p, miR-374-5p) is correlated with worse HNSCC prognosis.

Laryngeal squamous cell carcinoma (LSCC) is accounting for about $25 \%$ of the total head and neck cancer cases. ${ }^{141}$ Recently, two papers from the same group have reported that miR-195 significantly suppresses the growth and invasion of LSCC by targeting defects in cullin neddylation 1 , domain containing 1 (DCUN1D1). ${ }^{142}$ In addition, it favors Hep-2 apoptosis by silencing $B C L-2,{ }^{143}$ which would provide candidate targets for LSCC therapy. OSCC is also a common head and neck neoplasm with a poor prognosis. ${ }^{144}$ Repression of tripartite motif-containing protein 14 (TRIM14), which is involved in many biological processes though the NF- $\mathrm{\kappa B}$ signaling pathway, by miR-195 in OSCC cells results in proliferation, migration and invasion inhibition. ${ }^{145}$

Oral verrucous carcinoma (OVC) is a verrucous variant of OSCC. A study suggested a negative relationship between miR-195 and CDK6 and further verified that miR-195 and its target gene $C D K 6$ could be regarded as potential diagnostic biomarkers and therapeutic targets of OVC. ${ }^{146}$ These results suggested that miR-195 could serve as a potential therapeutic target and promising biomarker in head and neck cancer. Thus, miR-195 merits further exploration in future studies.

\section{miR- 195 and skin cancer Melanoma}

By far, melanoma is one of the most aggressive and deadly forms of skin cancer. Approximately 200,000 new cases and
46,000 deaths worldwide have been reported to be due to melanoma, with a 5 -year survival rate of $<15 \%$., ${ }^{1,147}$ Therefore, the diagnostic biomarkers and research to identify more effective treatment modalities are essential. Studies on the function of miR-195 in melanoma have drawn various but sometimes conflicting conclusions. One study on miR-195 in melanoma investigated the biological relevance of WEE1 and miR-195 in melanoma cell lines in vitro. Concretely, the authors discovered that miR-195 overexpression could enhance the migration and invasion of melanoma cells by directly inhibiting WEE1 expression. ${ }^{148}$ WEE1, a G2 checkpoint regulator, influences cell entry into mitosis by inhibiting $C D C 2$, which induces $\mathrm{G} 2 / \mathrm{M}$ progression in the cell cycle. ${ }^{149}$

Nevertheless, contrasting results have been revealed by Cirilo et al, ${ }^{150}$ who showed that miR-195 functions as an antiproliferative role in melanoma cells by targeting human prohibitin 1 gene $(P H B 1)$. PHB1 is a highly conserved protein, which is best known as a mitochondrial chaperone, and is required for the proliferation and growth of cancer cells. ${ }^{151}$ As a result, we explored whether miR-195 could function as an enhancer or a suppressor in the progression of melanoma tumors.

\section{miR-I95 and endocrine cancer}

\section{Breast cancer}

Globally, breast cancer is the leading cause of cancer death among females, accounting for approximately 1.5 million new cases per year. ${ }^{152}$ Distant metastasis and drug resistance have been regarded as major challenges in the treatment of breast cancer. ${ }^{153}$ Hence, it is a priority to identify reliable biomarkers that can predict tumor progression and drug responsiveness.

Several independent research groups have demonstrated an inhibitory effect of miR-195 on breast cancer development. Luo et al ${ }^{154}$ demonstrated that miR-195 is capable of inhibiting proliferation and colony formation in breast cancer cells in vitro by directly targeting a key cell cycle-related gene, CCNE1. CCNE1, which is one of the members of the cyclin family that drives cells from G1 to S phase, functions as an oncogene in many types of human cancers. ${ }^{155,156}$ In addition, miR-195 is also involved in lipid metabolism, which plays an important role in breast cancer. Acetyl-CoA carboxylase alpha $(A C A C A)$ and $F A S N$ are two key enzymes in de novo fatty acid synthesis, and they are highly elevated in breast cancer. ${ }^{157,158}$ As an important enzyme for do novo cholesterol synthesis, 3-hydroxy-3methylglutaryl-CoA reductase (HMGCR) is a potential 
anticancer molecule for breast cancer as well as other cancer types. ${ }^{159}$ Cytochrome P450 superfamily 27, subfamily B member 1 (CYP27B1) is upregulated in breast cancer and participates in calcium homeostasis and steroid biosynthesis, among other functions. ${ }^{160,161} \mathrm{miR}-195$ can significantly attenuate EMT in breast cancer via the downregulation of $A C A C A, F A S N, H M G C R$ and $C Y P 27 B 1$ by co-targeting their $3^{\prime}$-UTR regions. ${ }^{162}$ Wang et al ${ }^{163}$ established that miR-195 may be relevant to angiogenesis in the development of breast cancer. Mechanistically, miR-195 functions as a tumor suppressor in breast cancer via the IRS1-VEGF axis. It is well known that IRS1 is a signaling adapter protein involved in cancer progression, including breast cancer. ${ }^{164}$ The control of miR-195 expression may be related to epigenetic events, such as DNA methylation in breast cancer. Based on bisulfate restriction analysis and bisulfite sequencing, Li et $\mathrm{al}^{25}$ found that miR-195 and miR-197 are downregulated in human breast cancer tissues and cell lines due to the $\mathrm{CpG}$ islands upstream of the miR-195/497 gene methylation state. The authors identified miR-195 as a tumor suppressor that inhibits breast cancer cell colony formation and invasion in vitro partially by downregulating $R a f-1 .{ }^{25}$ Raf- 1 is a part of the MAPK/ REK signal transduction pathway and has been reported to undergo mutation into an oncogene in human tumors. ${ }^{165}$ Another study has illustrated that through inhibition of Raf-1, miR-195 upregulation sensitizes MCF-7 breast cancer cells to adriamycin treatment. ${ }^{166}$ Triple-negative breast cancer (TNBC) is a heterogeneous subtype of breast cancer characterized by the absence of estrogen, progesterone and HER-2 receptor expression, accounting for approximately $12 \%-17 \%$ of breast cancer cases, having a poor prognosis, and accompanied by a high risk of recurrence. ${ }^{167}$ Furuya et $\mathrm{al}^{168}$ reported that eribulin treatment strongly increases miR-195 levels in a non-basal-like type of TNBC cell line, MDA-MB-231, ${ }^{168}$ and miR-195 was reported to downregulate $\mathrm{Wnt} 3 \mathrm{a}$ in the same work.

There is emerging evidence supporting the prognostic role of miR-195 in breast cancer. For example, serum levels of miR-195 were clearly higher in the earliest stage of disease in Turkish breast cancer patients compared with disease-free controls. ${ }^{169}$ In addition, miR-195 has demonstrated utility in the prognosis of breast cancer, as reported by Nadeem et al, ${ }^{170}$ who demonstrated that the decrease in the expression of miR-195 in plasma samples of breast cancer patients was strikingly correlated with clinicopathological features, including a higher differentiation grade, lymph node metastasis and the clinical stage. Likewise, Zhao et $\mathrm{al}^{171}$ noted that the expression of miR-195 was notably downregulated in the serum of breast cancer patients and could be used to discriminate breast cancer from control samples with a sensitivity of $69.0 \%$ and specificity of $89.2 \%$. These results suggest that serum miR-195 may represent a novel diagnostic biomarker for breast cancer.

\section{Adrenocortical cancer (ACC)}

$\mathrm{ACC}$ is a rare but aggressive type of endocrine malignancy that occurs in approximately one to two people per million in the population. Patients with ACC generally have a poor outcome, with a 5-year survival rate of $30 \% .{ }^{172}$ Therefore, it is urgent to identify diagnostic and therapeutic biomarkers for this disease. According to the study by Soon et al, ${ }^{173} \mathrm{miR}-195$ is significantly downregulated in ACC and often inversely associated with poorer disease-specific survival. Subsequently, Carbra et $\mathrm{al}^{174}$ found that patients suffering from ACC have low circulating miR-195 and high miR-483-5p levels in serum, implying that circulating miR-195 and miR-483-5p could be promising predictive biomarkers with high prognostic value for ACC patients.

\section{Thyroid cancer}

Thyroid cancer is the most common endocrine-relevant cancer, and the incidence of which has been dramatically increasing worldwide in recent years. ${ }^{175}$ A study by Wang et $\mathrm{al}^{176}$ sought to expound the role of miR-195 in thyroid cancer. They reported that miR-195 was downregulated in 50 pairs of thyroid tumor tissues relative to the adjacent non-tumor tissues. Functional studies have suggested that miR-195 acts as a tumor suppressor by inhibiting thyroid cancer cell proliferation, and in vitro experiments have identified the proto-oncogene $R A F-1$ as a direct target of miR-195. ${ }^{176}$ A similar study has shown that miR-195 is underexpressed in papillary thyroid carcinoma (PTC). ${ }^{177}$ In that study, functional analyses suggested that miR-195 inhibits tumor growth by targeting $C C N D 1$ and suppresses migration and invasion by targeting FGF2 in PTC cells. Furthermore, miR-195 might suppress the Wnt/ $\beta$-catenin signaling pathway, which is critical in PTC pathogenesis. ${ }^{177}$ Thus, the abovementioned studies support miR-195 as a promising potential therapeutic target for thyroid cancer.

\section{Pancreatic cancer (PC)}

$\mathrm{PC}$, the fourth leading cause of cancer-related mortality in USA, continues to be one of the most aggressive malignancies, which is estimated to become the second leading cause of cancer death by $2030 .{ }^{178}$ There is a single report 
that miR-195 is a tumor-suppressive miRNA in PC, as miR-195 was expressed less in PC tissues and cell lines compared with normal controls. ${ }^{179}$ The overexpression of miR-195 in the PC cell line, AsPC-1, caused a reduction in proliferation, migration and invasion by negatively regulating doublecortin-like kinase 1 (DCLK1), whereas the downregulation of miR-195 had an opposite effect. ${ }^{179}$ DCLK1, a microtubule-binding member of the calmodulin-dependent kinase family, plays a key role in initiation and progression, which can also negatively regulate several tumor suppressor miRNAs. ${ }^{180,181}$

Overall, all the abovementioned studies suggest that miR-195 can act as a valuable biomarker for the diagnosis and prognosis of endocrine cancer.

\section{Conclusion}

In this review, we have focused on multiple mechanisms of miR-195 in various types of cancer and their potential roles in cancer diagnosis, differential prognosis and therapy evaluation. miR-195 is oncogenic or tumor suppressive and involved in a broad range of cancerous cellular processes, including proliferation, metastasis, invasion, apoptosis, angiogenesis (Figure 2) and chemosensitivity (Figure 3) or as a tumor promoter. The mechanisms by which miR-195 mediates its action are extremely complicated and involved in various signaling pathways, such as Rb-E2F, PI3K/AKT, NF- $\kappa$ B, MAPK/REK, Wnt/ $\beta$-catenin and Hippo/YAP. In molecular genetics, the $3^{\prime}$-UTR represents one section of $\mathrm{mRNA}$ that contains various binding sites for regulatory proteins as well as miRNAs that posttranscriptionally influence gene expression. Based on luciferase assays from all the studies reviewed herein, we determined that miR-195 could function as a tumor suppressor or promoter by binding to the $3^{\prime}$-UTR in the mRNA of its target genes in various cancers. ${ }^{25,37,75,86,112,162}$ In addition, the miR-195 and IncRNA regulatory paradigms modulate gene expression patterns that regulate tumor progression (such as cell proliferation, invasion and radiosensitivity; Figure 4). Greater recognition of the roles of miR-195 and lncRNAs in carcinogenesis could provide new insights into the mechanisms of tumor development and identify new diagnostic markers and therapeutic

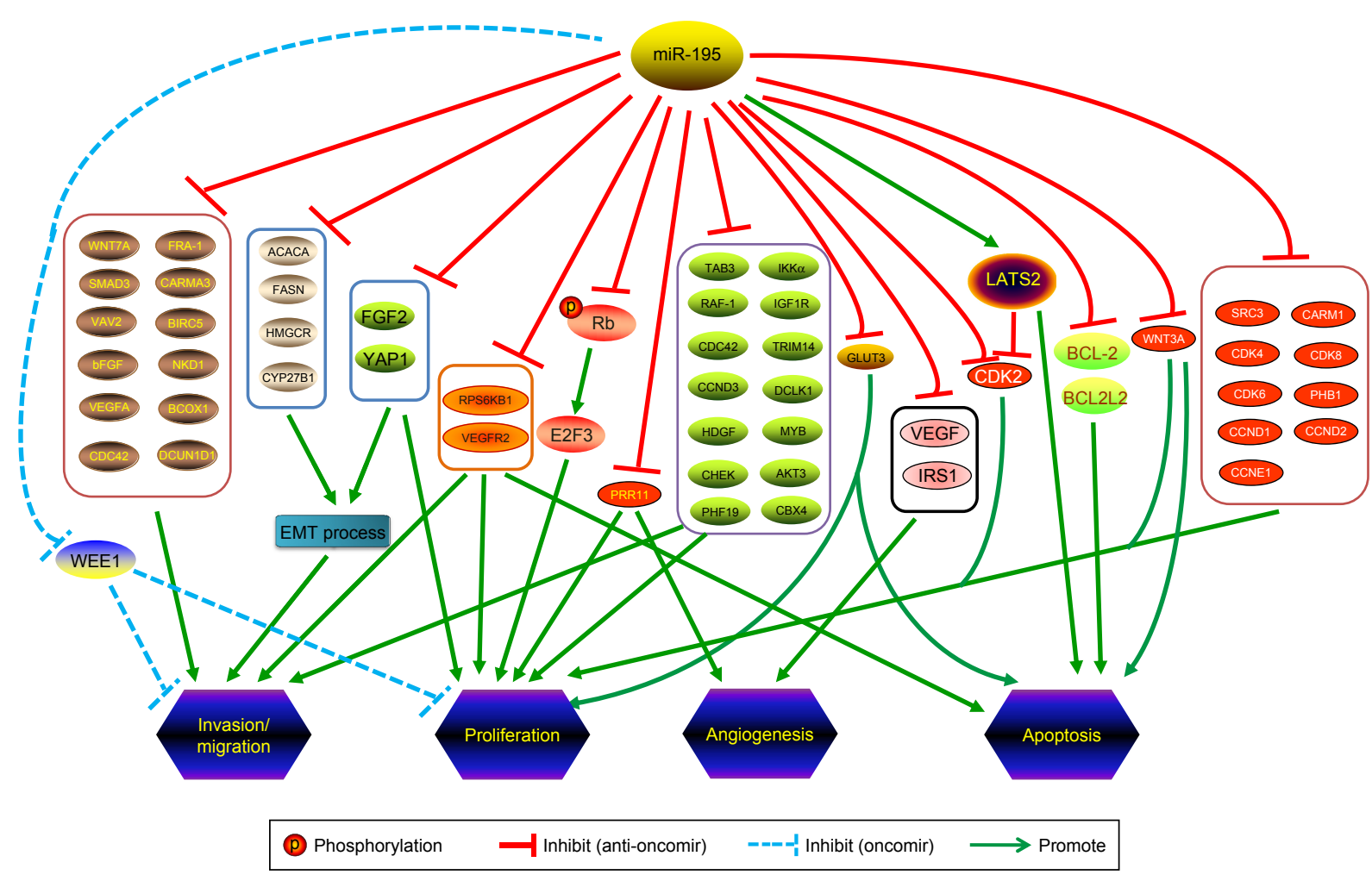

Figure 2 Roles of miR-195 in the progression and development of malignant tumors and its target genes.

Note: The direct targets and indirect effectors of miR-195 are shown with their multiple functions in cancer cell processes (EMT, invasion/migration, proliferation, angiogenesis and apoptosis).

Abbreviation: EMT, epithelial-mesenchymal transition. 


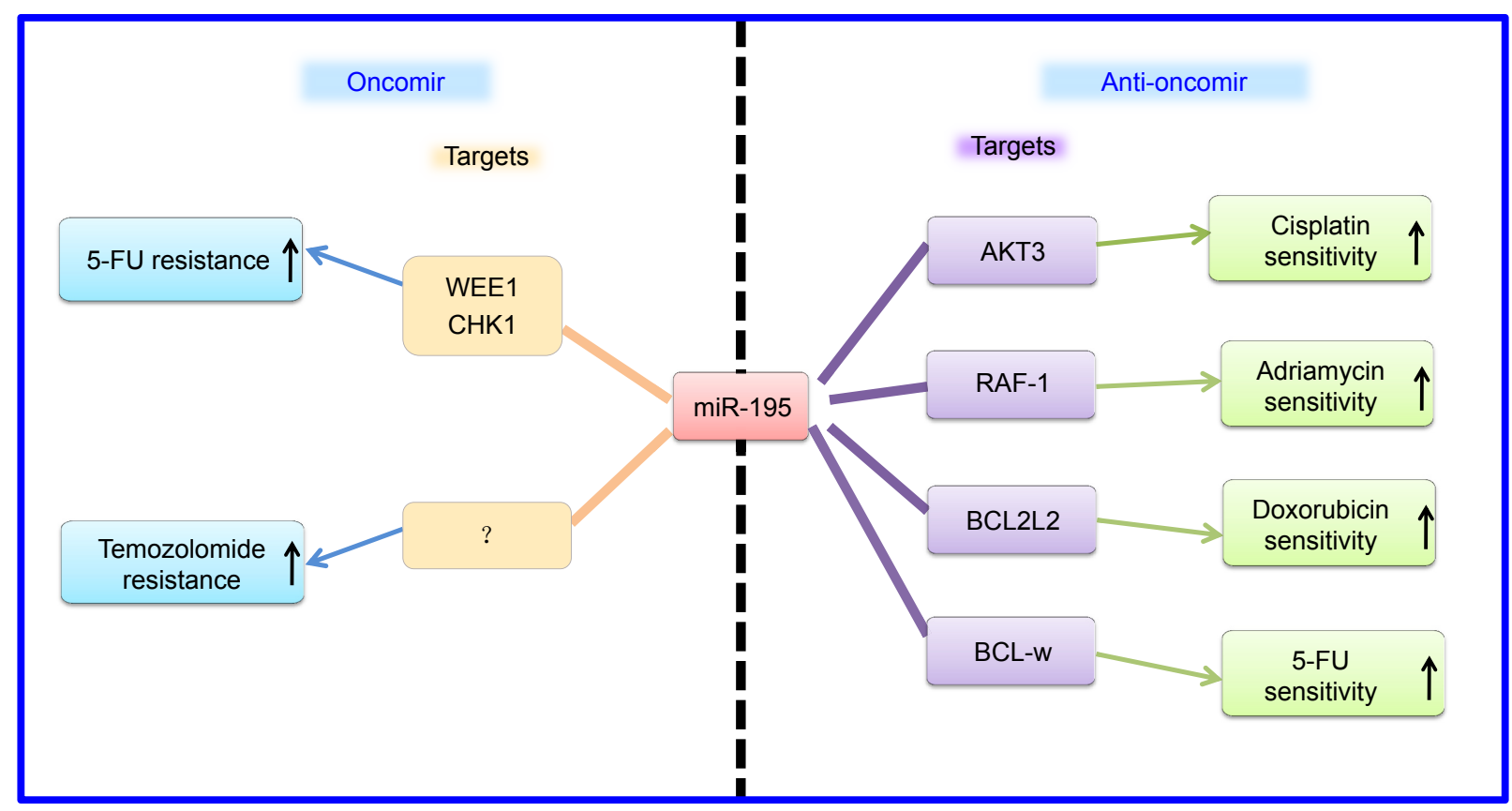

Figure 3 Summary of the diverse roles of miR-195 in drug sensitivity. Abbreviation: 5-FU, 5-fluorouracil.

approaches for anticancer drug development. Nevertheless, the complex mechanisms of miR-195 involved in cancer development are still in the early stage, which should be systematically explored. Therefore, multicenter studies are needed before the experimental findings for miR195 can be applied in the clinic to treat various types of human cancers.

In conclusion, the current review indicates that miR-195 may act as a potentially useful tumor biomarker for cancer diagnosis and therapy. Combined use of miR-195 and other conventional tumor markers may be a promising direction for clinical diagnosis.

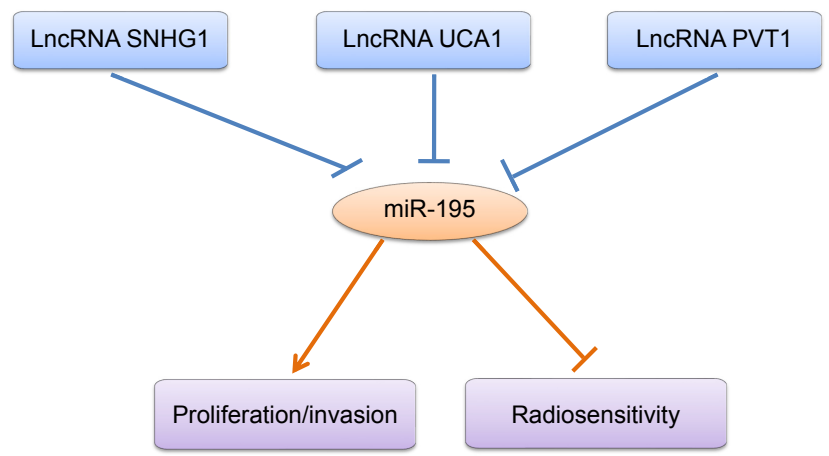

Figure 4 Roles of miR-195 and LncRNA-miR-195 interactions in regulating tumor progression.

\section{Acknowledgment}

This work was supported by the National Natural Science Foundation of China (grant no 31601194) and Natural Science Foundation of Shandong Province (JQ201815).

\section{Disclosure}

The authors report no conflicts of interest in this work.

\section{References}

1. Ferlay J, Soerjomataram I, Dikshit R, et al. Cancer incidence and mortality worldwide: sources, methods and major patterns in GLOBOCAN 2012. Int J Cancer. 2015;136(5):E359-E386.

2. Malvezzi M, Carioli G, Bertuccio P, et al. European cancer mortality predictions for the year 2017, with focus on lung cancer. Ann Oncol. 2017; 28(5):1117-1123

3. Bartel DP. MicroRNAs: genomics, biogenesis, mechanism, and function Cell. 2004;116(2):281-297.

4. Lee RC, Feinbaum RL, Ambros V. The C. elegans heterochronic gene lin-4 encodes small RNAs with antisense complementarity to lin-14. Cell. 1993;75(5):843-854.

5. Ameres SL, Zamore PD. Diversifying microRNA sequence and function Nat Rev Mol Cell Biol. 2013;14(8):475-488.

6. Bartel DP. MicroRNAs: target recognition and regulatory functions. Cell. 2009;136(2):215-233.

7. Vidigal JA, Ventura A. The biological functions of miRNAs: lessons from in vivo studies. Trends Cell Biol. 2015;25(3):137-147.

8. Berezikov E, Guryev V, van de Belt J, Wienholds E, Plasterk RH, Cuppen E. Phylogenetic shadowing and computational identification of human microRNA genes. Cell. 2005;120(1):21-24.

9. Rajewsky N. microRNA target predictions in animals. Nat Genet. 2006; 38(Suppl 6):S8-S13. 
10. Rodriguez A, Griffiths-Jones S, Ashurst JL, Bradley A. Identification of mammalian microRNA host genes and transcription units. Genome Res. 2004;14(10A):1902-1910.

11. Robey RW, Steadman K, Polgar O, Bates SE. ABCG2-mediated transport of photosensitizers: Potential impact on photodynamic therapy. Cancer Biol Ther. 2005;4(2):195-202.

12. Lewis BP, Burge CB, Bartel DP. Conserved seed pairing, often flanked by adenosines, indicates that thousands of human genes are microRNA targets. Cell. 2005;120(1):15-20.

13. Wu YR, Qi HJ, Deng DF, Luo YY, Yang SL. MicroRNA-21 promotes cell proliferation, migration, and resistance to apoptosis through PTEN/ PI3K/AKT signaling pathway in esophageal cancer. Tumour Biol. 2016; 37(9):12061-12070

14. Poy MN, Eliasson L, Krutzfeldt J, et al. A pancreatic islet-specific microRNA regulates insulin secretion. Nature. 2004;432(7014): 226-230.

15. Karp X, Ambros V. Developmental biology. Encountering microRNAs in cell fate signaling. Science. 2005;310(5752):1288-1289.

16. Cheng AM, Byrom MW, Shelton J, Ford LP. Antisense inhibition of human miRNAs and indications for an involvement of miRNA in cell growth and apoptosis. Nucleic Acids Res. 2005;33(4):1290-1297.

17. Chan B, Manley J, Lee J, Singh SR. The emerging roles of microRNAs in cancer metabolism. Cancer Lett. 2015;356(2 Pt A):301-308.

18. Baranwal S, Alahari SK. miRNA control of tumor cell invasion and metastasis. Int J Cancer. 2010;126(6):1283-1290.

19. Hata A, Kashima R. Dysregulation of microRNA biogenesis machinery in cancer. Crit Rev Biochem Mol Biol. 2016;51(3):121-134.

20. Finnerty JR, Wang WX, Hébert SS, Wilfred BR, Mao G, Nelson PT. The miR-15/107 group of microRNA genes: evolutionary biology, cellular functions, and roles in human diseases. J Mol Biol. 2010;402(3): 491-509.

21. Flavin RJ, Smyth PC, Laios A, et al. Potentially important microRNA cluster on chromosome $17 \mathrm{p} 13.1$ in primary peritoneal carcinoma. Mod Pathol. 2009;22(2):197-205.

22. He JF, Luo YM, Wan XH, Jiang D. Biogenesis of MiRNA-195 and its role in biogenesis, the cell cycle, and apoptosis. J Biochem Mol Toxicol. 2011;25(6):404-408.

23. Guo AY, Sun J, Jia P, Zhao Z. A novel microRNA and transcription factor mediated regulatory network in schizophrenia. BMC Syst Biol. 2010;4(1):10.

24. van Rooij E, Sutherland LB, Liu N, et al. A signature pattern of stressresponsive microRNAs that can evoke cardiac hypertrophy and heart failure. Proc Natl Acad Sci U S A. 2006;103(48):18255-18260.

25. Li D, Zhao Y, Liu C, et al. Analysis of MiR-195 and MiR-497 expression, regulation and role in breast cancer. Clin Cancer Res. 2011;17(7): 1722-1730.

26. Volinia S, Calin GA, Liu CG, et al. A microRNA expression signature of human solid tumors defines cancer gene targets. Proc Natl Acad Sci US A. 2006;103(7):2257-2261.

27. Deng H, Guo Y, Song H, et al. MicroRNA-195 and microRNA-378 mediate tumor growth suppression by epigenetical regulation in gastric cancer. Gene. 2013;518(2):351-359.

28. Guo ST, Jiang CC, Wang GP, et al. MicroRNA-497 targets insulin-like growth factor 1 receptor and has a tumour suppressive role in human colorectal cancer. Oncogene. 2013;32(15):1910-1920.

29. Itesako $\mathrm{T}$, Seki N, Yoshino $\mathrm{H}$, et al. The microRNA expression signature of bladder cancer by deep sequencing: the functional significance of the miR-195/497 cluster. PLoS One. 2014;9(2):e84311.

30. Forner A, Llovet JM, Bruix J. Hepatocellular carcinoma. Lancet. 2012;379(9822):1245-1255.

31. Xu T, Zhu Y, Xiong Y, Ge YY, Yun JP, Zhuang SM. MicroRNA-195 suppresses tumorigenicity and regulates G1/S transition of human hepatocellular carcinoma cells. Hepatology. 2009;50(1):113-121.

32. Yang X, Yu J, Yin J, Xiang Q, Tang H, Lei X. MiR-195 regulates cell apoptosis of human hepatocellular carcinoma cells by targeting LATS2. Pharmazie. 2012;67(7):645-651.

33. Li Y, Pei J, Xia H, Ke H, Wang H, Tao W. Lats2, a putative tumor suppressor, inhibits G1/S transition. Oncogene. 2003;22(28):4398-4405.
34. Ben-Neriah Y, Karin M. Inflammation meets cancer, with NF- $\kappa B$ as the matchmaker. Nat Immunol. 2011;12(8):715-723.

35. Ding J, Huang S, Wang Y, et al. Genome-wide screening reveals that miR-195 targets the TNF- $\alpha / N F-\kappa B$ pathway by down-regulating I $\kappa$ B kinase alpha and TAB3 in hepatocellular carcinoma. Hepatology. 2013;58(2):654-666.

36. Wang R, Zhao N, Li S, et al. MicroRNA-195 suppresses angiogenesis and metastasis of hepatocellular carcinoma by inhibiting the expression of VEGF, VAV2, and CDC42. Hepatology. 2013;58(2):642-653.

37. Amer M, Elhefnawi M, El-Ahwany E, et al. Hsa-miR-195 targets PCMT1 in hepatocellular carcinoma that increases tumor life span. Tumour Biol. 2014;35(11):11301-11309.

38. Yang Y, Li M, Chang S, et al. MicroRNA-195 acts as a tumor suppressor by directly targeting Wnt3a in HepG2 hepatocellular carcinoma cells. Mol Med Rep. 2014;10(5):2643-2648.

39. Ilyas M. Wnt signalling and the mechanistic basis of tumour development. J Pathol. 2005;205(2):130-144.

40. Tien JC, Xu J. Steroid receptor coactivator-3 as a potential molecular target for cancer therapy. Expert Opin Ther Targets. 2012;16(11): 1085-1096.

41. Jiang HL, Yu H, Ma X, et al. MicroRNA-195 regulates steroid receptor coactivator-3 protein expression in hepatocellular carcinoma cells. Tumour Biol. 2014;35(7):6955-6960.

42. Zheng C, Li J, Wang Q, et al. MicroRNA-195 functions as a tumor suppressor by inhibiting CBX4 in hepatocellular carcinoma. Oncol Rep. 2015;33(3):1115-1122.

43. Xu H, Hu YW, Zhao JY, et al. MicroRNA-195-5p acts as antioncogene by targeting PHF19 in hepatocellular carcinoma. Oncol Rep. 2015;34(1):175-182.

44. Wang M, Zhang J, Tong L, Ma X, Qiu X. MiR-195 is a key negative regulator of hepatocellular carcinoma metastasis by targeting FGF2 and VEGFA. Int J Clin Exp Pathol. 2015;8(11):14110-14120.

45. Yu S, Jing L, Yin XR, et al. MiR-195 suppresses the metastasis and epithelial-mesenchymal transition of hepatocellular carcinoma by inhibiting YAP. Oncotarget. 2017;8(59):99757-99771.

46. Zhang H, Zhou D, Ying M, et al. Expression of Long Non-Coding RNA (lncRNA) Small Nucleolar RNA Host Gene 1 (SNHG1) Exacerbates Hepatocellular Carcinoma Through Suppressing miR-195. Med Sci Monit. 2016;22:4820-4829.

47. Yang X, Yin J, Yu J, et al. miRNA-195 sensitizes human hepatocellular carcinoma cells to 5-FU by targeting BCL-w. Oncol Rep. 2012; 27(1):250-257.

48. Sohn W, Kim J, Kang SH, et al. Serum exosomal microRNAs as novel biomarkers for hepatocellular carcinoma. Exp Mol Med. 2015; 47(9):e184.

49. Siegel R, Desantis C, Jemal A. Colorectal cancer statistics, 2014. CA Cancer J Clin. 2014;64(2):104-117.

50. Wang N, Lu Y, Khankari NK, et al. Evaluation of genetic variants in association with colorectal cancer risk and survival in Asians. Int $J$ Cancer. 2017;141(6):1130-1139.

51. Liu L, Chen L, Xu Y, Li R, Du X. microRNA-195 promotes apoptosis and suppresses tumorigenicity of human colorectal cancer cells. Biochem Biophys Res Commun. 2010;400(2):236-240.

52. Zhang X, Xu J, Jiang T, Liu G, Wang D, Lu Y. MicroRNA-195 suppresses colorectal cancer cells proliferation via targeting FGF2 and regulating Wnt/ $\beta$-catenin pathway. Am J Cancer Res. 2016;6(11):2631-2640.

53. Luo Q, Zhang Z, Dai Z, et al. Tumor-suppressive microRNA-195-5p regulates cell growth and inhibits cell cycle by targeting cyclin dependent kinase 8 in colon cancer. Am J Transl Res. 2016;8(5):2088-2096.

54. Yang B, Tan Z, Song Y. Study on the molecular regulatory mechanism of MicroRNA-195 in the invasion and metastasis of colorectal carcinoma. Int J Clin Exp Med. 2015;8(3):3793-3800.

55. Wang X, Wang J, Ma H, Zhang J, Zhou X. Downregulation of miR-195 correlates with lymph node metastasis and poor prognosis in colorectal cancer. Med Oncol. 2012;29(2):919-927.

56. Wang L, Qian L, Li X, Yan J. MicroRNA-195 inhibits colorectal cancer cell proliferation, colony-formation and invasion through targeting CARMA3. Mol Med Rep. 2014;10(1):473-478. 
57. Zhao T, Miao Z, Wang Z, et al. CARMA3 overexpression accelerates cell proliferation and inhibits paclitaxel-induced apoptosis through NF- $\mathrm{KB}$ regulation in breast cancer cells. Tumour Biol. 2013;34(5): 3041-3047.

58. Sun M, Song H, Wang S, et al. Integrated analysis identifies microRNA195 as a suppressor of Hippo-YAP pathway in colorectal cancer. J Hematol Oncol. 2017;10(1):79.

59. Li K, Zhou ZY, Ji PP, Luo HS. Knockdown of $\beta$-catenin by siRNA influences proliferation, apoptosis and invasion of the colon cancer cell line SW480. Oncol Lett. 2016;11(6):3896-3900.

60. Jibiki N, Saito N, Kameoka S, Kobayashi M. Clinical significance of fibroblast growth factor (FGF) expression in colorectal cancer. Int Surg. 2014;99(5):493-499.

61. Ye S, Song W, Xu X, Zhao X, Yang L. IGF2BP2 promotes colorectal cancer cell proliferation and survival through interfering with $R A F-1$ degradation by miR-195. FEBS Lett. 2016;590(11):1641-1650.

62. Chong H, Vikis HG, Guan KL. Mechanisms of regulating the Raf kinase family. Cell Signal. 2003;15(5):463-469.

63. Hummel R, Hussey DJ, Haier J. MicroRNAs: predictors and modifiers of chemo- and radiotherapy in different tumour types. Eur J Cancer. 2010;46(2):298-311.

64. Zheng L, Chen J, Zhou Z, He Z. miR-195 enhances the radiosensitivity of colorectal cancer cells by suppressing CARM1. Onco Target Ther 2017;10:1027-1038

65. Wang L, Zhao Z, Meyer MB, et al. CARM1 Methylates Chromatin Remodeling Factor BAF155 to Enhance Tumor Progression and Metastasis. Cancer Cell. 2016;30(1):179-180.

66. Wang YP, Zhou W, Wang J, et al. Arginine Methylation of MDH1 by CARM1 Inhibits Glutamine Metabolism and Suppresses Pancreatic Cancer. Mol Cell. 2016;64(4):673-687.

67. Qu J, Zhao L, Zhang P, et al. MicroRNA-195 chemosensitizes colon cancer cells to the chemotherapeutic drug doxorubicin by targeting the first binding site of BCL2L2 mRNA. J Cell Physiol. 2015;230(3): 535-545.

68. Kim C, Hong Y, Lee H, Kang H, Lee EK. MicroRNA-195 desensitizes HCT116 human colon cancer cells to 5-fluorouracil. Cancer Lett. 2018;412:264-271.

69. Li HG, Zhao LH, Bao XB, Sun PC, Zhai BP. Meta-analysis of the differentially expressed colorectal cancer-related microRNA expression profiles. Eur Rev Med Pharmacol Sci. 2014;18(14):2048-2057.

70. Jemal A, Bray F, Center MM, Ferlay J, Ward E, Forman D. Global cancer statistics. CA Cancer J Clin. 2011;61(2):69-90.

71. Marin JJ, Al-Abdulla R, Lozano E, et al. Mechanisms of Resistance to Chemotherapy in Gastric Cancer. Anticancer Agents Med Chem. 2016; 16(3):318-334.

72. Song J, Bai Z, Zhang Z. MicroRNAs are implicated in the initiation and progression of gastric cancer. Chin Med J. 2014;127(3):554-559.

73. Ye R, Wei B, Li S, et al. Expression of miR-195 is associated with chemotherapy sensitivity of cisplatin and clinical prognosis in gastric cancer. Oncotarget. 2017;8(57):97260-97272.

74. Ahmad A, Biersack B, Li Y, et al. Targeted regulation of PI3K/Akt/ mTOR/NF- $\mathrm{KB}$ signaling by indole compounds and their derivatives: mechanistic details and biological implications for cancer therapy. Anticancer Agents Med Chem. 2013;13(7):1002-1013.

75. Wang J, Li L, Jiang M, Li Y. MicroRNA-195 inhibits human gastric cancer by directly targeting basic fibroblast growth factor. Clin Transl Oncol. 2017;19(11):1320-1328.

76. Coleman SJ, Chioni AM, Ghallab M, et al. Nuclear translocation of FGFR1 and FGF2 in pancreatic stellate cells facilitates pancreatic cancer cell invasion. EMBO Mol Med. 2014;6(4):467-481.

77. Shen YH, Xie ZB, Yue AM, et al. Expression level of microRNA-195 in the serum of patients with gastric cancer and its relationship with the clinicopathological staging of the cancer. Eur Rev Med Pharmacol Sci. 2016;20(7):1283-1287.

78. Zhang Y. Epidemiology of esophageal cancer. World J Gastroenterol. 2013;19(34):5598-5606.

79. Jemal A, Siegel R, Xu J, Ward E. Cancer statistics, 2010. CA Cancer J Clin.. 2010;60(5):277-300.
80. Fu HL, Wu DP, Wang XF, et al. Altered miRNA expression is associated with differentiation, invasion, and metastasis of esophageal squamous cell carcinoma (ESCC) in patients from Huaian, China. Cell Biochem Biophys. 2013;67(2):657-668.

81. Fu MG, Li S, Yu TT, et al. Differential expression of miR-195 in esophageal squamous cell carcinoma and miR-195 expression inhibits tumor cell proliferation and invasion by targeting of Cdc42. FEBS Lett. 2013;587(21):3471-3479.

82. Stengel K, Zheng Y. Cdc42 in oncogenic transformation, invasion, and tumorigenesis. Cell Signal. 2011;23(9):1415-1423.

83. Sun N, Ye L, Chang T, Li X, Li X. microRNA-195-Cdc42 axis acts as a prognostic factor of esophageal squamous cell carcinoma. Int $J$ Clin Exp Pathol. 2014;7(10):6871-6879.

84. Siegel R, Ward E, Brawley O, Jemal A. Cancer statistics, 2011: the impact of eliminating socioeconomic and racial disparities on premature cancer deaths. CA Cancer J Clin. 2011;61(4):212-236.

85. Yongchun Z, Linwei T, Xicai W, et al. MicroRNA-195 inhibits nonsmall cell lung cancer cell proliferation, migration and invasion by targeting MYB. Cancer Lett. 2014;347(1):65-74.

86. Wang X, Wang Y, Lan H, Li J. MiR-195 inhibits the growth and metastasis of NSCLC cells by targeting IGF1R. Tumour Biol. 2014; 35(9):8765-8770.

87. Kang HS, Ahn SH, Mishra SK, et al. Association of polymorphisms and haplotypes in the insulin-like growth factor 1 receptor (IGF1R) gene with the risk of breast cancer in Korean women. PLoS One. 2014;9(1):e84532.

88. Guo H, Li W, Zheng T, Liu Z. MiR-195 targets HDGF to inhibit proliferation and invasion of NSCLC cells. Tumour Biol. 2014;35(9): 8861-8866.

89. Liu B, Qu J, Xu F, et al. MiR-195 suppresses non-small cell lung cancer by targeting CHEK1. Oncotarget. 2015;6(11):9445-9456.

90. Wu D, Li Y, Zhang H, Hu X. Knockdown of Lncrna PVT1 Enhances Radiosensitivity in Non-Small Cell Lung Cancer by Sponging Mir195. Cell Physiol Biochem. 2017;42(6):2453-2466.

91. GBD 2015 Disease and Injury Incidence and Prevalence Collaborators. Global, regional, and national incidence, prevalence, and years lived with disability for 310 diseases and injuries, 1990-2015: a systematic analysis for the Global Burden of Disease Study 2015. Lancet. 2016;388(10053):1545-1602.

92. Ferlay J, Shin HR, Bray F, Forman D, Mathers C, Parkin DM. Estimates of worldwide burden of cancer in 2008: GLOBOCAN 2008. Int J Cancer. 2010;127(12):2893-2917.

93. Kim WJ, Bae SC. Molecular biomarkers in urothelial bladder cancer Cancer Sci. 2008;99(4):646-652.

94. Canturk KM, Ozdemir M, Can C, et al. Investigation of key miRNAs and target genes in bladder cancer using miRNA profiling and bioinformatic tools. Mol Biol Rep. 2014;41(12):8127-8135.

95. Dickson MA. Molecular pathways: CDK4 inhibitors for cancer therapy. Clin Cancer Res. 2014;20(13):3379-3383.

96. Lin Y, Wu J, Chen H, et al. Cyclin-dependent kinase 4 is a novel target in micoRNA-195-mediated cell cycle arrest in bladder cancer cells. FEBS Lett. 2012;586(4):442-447.

97. Fei X, Qi M, Wu B, Song Y, Wang Y, Li T. MicroRNA-195-5p suppresses glucose uptake and proliferation of human bladder cancer T24 cells by regulating GLUT3 expression. FEBS Lett. 2012;586(4): 392-397.

98. Palfreyman RW, Clark AE, Denton RM, Holman GD, Kozka IJ. Kinetic resolution of the separate GLUT1 and GLUT4 glucose transport activities in 3T3-L1 cells. Biochem J. 1992;284 (Pt 1):275-282.

99. Kanwar JR, Kamalapuram SK, Kanwar RK. Survivin signaling in clinical oncology: a multifaceted dragon. Med Res Rev. 2013;33(4):765-789.

100. $\mathrm{Ku}$ JH, Godoy G, Amiel GE, Lerner SP. Urine survivin as a diagnostic biomarker for bladder cancer: a systematic review. BJU Int. 2012;110(5):630-636.

101. Zhao C, Qi L, Chen M, et al. microRNA-195 inhibits cell proliferation in bladder cancer via inhibition of cell division control protein 42 homolog/signal transducer and activator of transcription-3 signaling. Exp Ther Med. 2015;10(3):1103-1108. 
102. Wang F, Li X, Xie X, Zhao L, Chen W. UCA1, a non-protein-coding RNA up-regulated in bladder carcinoma and embryo, influencing cell growth and promoting invasion. FEBS Lett. 2008;582(13):1919-1927.

103. Hj L, Sun XM, Li ZK, et al. LncRNA UCA1 Promotes Mitochondrial Function of Bladder Cancer via the MiR-195/ARL2 Signaling Pathway. Cell Physiol Biochem. 2017;43(6):2548-2561.

104. Nishi H, Ono K, Iwanaga Y, et al. MicroRNA-15b modulates cellular ATP levels and degenerates mitochondria via Arl2 in neonatal rat cardiac myocytes. J Biol Chem. 2010;285(7):4920-4930.

105. Newman LE, Schiavon CR, Zhou C, Kahn RA. The abundance of the ARL2 GTPase and its GAP, ELMOD2, at mitochondria are modulated by the fusogenic activity of mitofusins and stressors. PLoS One. 2017;12(4):e0175164.

106. Siegel R, Ma J, Zou Z, Jemal A. Cancer statistics, 2014. CA Cancer J Clin. 2014;64(1):9-29.

107. Rasmussen F. Metastatic renal cell cancer. Cancer Imaging. 2013; 13(3):374-380.

108. Sun P, Wang L, Lu Y, et al. MicroRNA-195 targets VEGFR2 and has a tumor suppressive role in ACHN cells via PI3K/Akt and Raf/MEK/ ERK signaling pathways. Int J Oncol. 2016;49(3):1155-1163.

109. Wang K, Sun Y, Tao W, Fei X, Chang C. Androgen receptor (AR) promotes clear cell renal cell carcinoma (ccRCC) migration and invasion via altering the circHIAT1/miR-195-5p/29a-3p/29c-3p/CDC42 signals. Cancer Lett. 2017;394:1-12.

110. Zhang Y, Zhang D, Wang F, Xu D, Guo Y, Cui W. Serum miRNAs panel (miR-16-2*, miR-195, miR-2861, miR-497) as novel noninvasive biomarkers for detection of cervical cancer. Sci Rep. 2016; $5(1): 17942$.

111. Song R, Cong L, Ni G, et al. MicroRNA-195 inhibits the behavior of cervical cancer tumors by directly targeting HDGF. Oncol Lett. 2017; 14(1):767-775.

112. Wang N, Wei H, Yin D, et al. MicroRNA-195 inhibits proliferation of cervical cancer cells by targeting cyclin D1a. Tumour Biol. 2016; 37(4):4711-4720.

113. Du X, Lin LI, Zhang L, Jiang J. microRNA-195 inhibits the proliferation, migration and invasion of cervical cancer cells via the inhibition of CCND2 and MYB expression. Oncol Lett. 2015;10(4):2639-2643.

114. Li Z, Wang H, Wang Z, Cai H. MiR-195 inhibits the proliferation of human cervical cancer cells by directly targeting cyclin D1. Tumour Biol. 2016;37(5):6457-6463.

115. Zhou Q, Han LR, Zhou YX, Li Y. MiR-195 Suppresses Cervical Cancer Migration and Invasion Through Targeting Smad3. Int J Gynecol Cancer. 2016;26(5):817-824.

116. de Caestecker MP, Piek E, Roberts AB. Role of transforming growth factor-beta signaling in cancer. J Natl Cancer Inst. 2000;92(17): $1388-1402$.

117. Guo J, Wang M, Liu X. MicroRNA-195 suppresses tumor cell proliferation and metastasis by directly targeting BCOX1 in prostate carcinoma. J Exp Clin Cancer Res. 2015;34(1):91.

118. Liu C, Guan H, Wang Y, et al. miR-195 Inhibits EMT by Targeting FGF2 in Prostate Cancer Cells. PLoS One. 2015;10(12):e144073.

119. Wu J, Ji A, Wang X, et al. MicroRNA-195-5p, a new regulator of Fra-1, suppresses the migration and invasion of prostate cancer cells. J Transl Med. 2015;13(1):289.

120. Cai C, Chen QB, Han ZD, et al. miR-195 Inhibits Tumor Progression by Targeting RPS6KB1 in Human Prostate Cancer. Clin Cancer Res. 2015;21(21):4922-4934.

121. Cai C, He H, Duan X, et al. miR-195 inhibits cell proliferation and angiogenesis in human prostate cancer by downregulating PRR11 expression. Oncol Rep. 2018;39(4):1658-1670.

122. Mirabello L, Troisi RJ, Savage SA. Osteosarcoma incidence and survival rates from 1973 to 2004: data from the Surveillance, Epidemiology, and End Results Program. Cancer. 2009;115(7):1531-1543.

123. Lian F, Cui Y, Zhou C, Gao K, Wu L. Identification of a plasma four-microRNA panel as potential noninvasive biomarker for osteosarcoma. PLoS One. 2015;10(3):e0121499.
124. Mao JH, Zhou RP, Peng AF, et al. microRNA-195 suppresses osteosarcoma cell invasion and migration in vitro by targeting FASN. Oncol Lett. 2012;4(5):1125-1129.

125. Carvalho MA, Zecchin KG, Seguin F, et al. Fatty acid synthase inhibition with Orlistat promotes apoptosis and reduces cell growth and lymph node metastasis in a mouse melanoma model. Int $J$ Cancer. 2008;123(11):2557-2565.

126. Murata S, Yanagisawa K, Fukunaga K, et al. Fatty acid synthase inhibitor cerulenin suppresses liver metastasis of colon cancer in mice. Cancer Sci. 2010;101(8):1861-1865.

127. Han K, Chen X, Bian N, et al. MicroRNA profiling identifies MiR-195 suppresses osteosarcoma cell metastasis by targeting CCND1. Oncotarget. 2015;6(11):8875-8889.

128. Qu Q, Chu X, Wang P. MicroRNA-195-5p suppresses osteosarcoma cell proliferation and invasion by suppressing naked cuticle homolog 1. Cell Biol Int. 2017;41(3):287-295.

129. Yan D, Wiesmann M, Rohan M, et al. Elevated expression of axin2 and hnkd mRNA provides evidence that $\mathrm{Wnt} /$-catenin signaling is activated in human colon tumors. Proc Natl Acad Sci U S A. 2001;98(26): 14973-14978.

130. Koch A, Waha A, Hartmann W, et al. Elevated expression of Wnt antagonists is a common event in hepatoblastomas. Clin Cancer Res. 2005;11(12):4295-4304.

131. Wen PY, Kesari S. Malignant Gliomas in Adults. $N$ Engl J Med Overseas Ed. 2008;359(5):492-507.

132. Lakomy R, Sana J, Hankeova S, et al. MiR-195, miR-196b, miR-181c, miR-21 expression levels and O-6-methylguanine-DNA methyltransferase methylation status are associated with clinical outcome in glioblastoma patients. Cancer Sci. 2011;102(12):2186-2190.

133. Zhang QQ, Xu H, Huang MB, et al. MicroRNA-195 plays a tumorsuppressor role in human glioblastoma cells by targeting signaling pathways involved in cellular proliferation and invasion. Neuro Oncol. 2012;14(3):278-287.

134. Hui W, Yuntao L, Lun L, et al. MicroRNA-195 inhibits the proliferation of human glioma cells by directly targeting cyclin D1 and cyclin E1. PLoS One. 2013;8(1):e54932.

135. Ujifuku K, Mitsutake N, Takakura S, et al. miR-195, miR-455-3p and miR-10a $(*)$ are implicated in acquired temozolomide resistance in glioblastoma multiforme cells. Cancer Lett. 2010;296(2):241-248.

136. Yilaz Susluer S, Biray Avci C, Dodurga Y, Ozlem Dogan Sigva Z, Oktar N, Gunduz C. Downregulation of miR-195 via cyclosporin A in human glioblastoma cells. J BUON. 2015;20(5):1337-1340.

137. Parkin DM, Bray F, Ferlay J, Pisani P. Global cancer statistics, 2002. CA Cancer J Clin. 2005;55(2):74-108.

138. Jia LF, Wei SB, Gong K, Gan YH, Yu GY. Prognostic implications of microRNA miR-195 expression in human tongue squamous cell carcinoma. PLoS One. 2013;8(2): e56634.

139. Santos PRB, Coutinho-Camillo CM, Soares FA, et al. MicroRNAs expression pattern related to mast cell activation and angiogenesis in paraffin-embedded salivary gland tumors. Pathol Res Pract. 2017; 213(12):1470-1476.

140. Summerer I, Unger K, Braselmann H, et al. Circulating microRNAs as prognostic therapy biomarkers in head and neck cancer patients. Br J Cancer. 2015;113(1):76-82.

141. Siegel R, Naishadham D, Jemal A. Cancer statistics, 2013. CA Cancer J Clin. 2013;63(1):11-30.

142. Shuang Y, Li C, Zhou X, Huang Y, Zhang L. MicroRNA-195 inhibits growth and invasion of laryngeal carcinoma cells by directly targeting DCUN1D1. Oncol Rep. 2017;38(4):2155-2165.

143. Shuang Y, Li C, Zhou X, Huang YW, Zhang L. Expression of miR-195 in laryngeal squamous cell carcinoma and its effect on proliferation and apoptosis of Hep-2. Eur Rev Med Pharmacol Sci. 2017;21(14): 3232-3238.

144. Wang B, Zhang S, Yue K, Wang XD. The recurrence and survival of oral squamous cell carcinoma: a report of 275 cases. Chin J Cancer. 2013;32(11):614-618. 
145. Wang T, Ren Y, Liu R, et al. miR-195-5p Suppresses the Proliferation, Migration, and Invasion of Oral Squamous Cell Carcinoma by Targeting TRIM14. Biomed Res Int. 2017;2017:7378148.

146. Deng Z, Wang Y, Fang X, et al. Research on miRNA-195 and target gene CDK6 in oral verrucous carcinoma. Cancer Gene Ther. 2017; 24(7):282-288.

147. Siegel RL, Miller KD, Jemal A. Cancer statistics, 2016. CA Cancer J Clin. 2016;66(1):7-30.

148. Bhattacharya A, Schmitz U, Wolkenhauer O, Schönherr M, Raatz Y, Kunz M. Regulation of cell cycle checkpoint kinase WEE1 by miR-195 in malignant melanoma. Oncogene. 2013;32(26):3175-3183.

149. Mcgowan CH, Russell P. Human Weel kinase inhibits cell division by phosphorylating p34cdc2 exclusively on Tyr15. EMBO J. 1993; 12(1):75-85.

150. Cirilo PDR, de Sousa Andrade LN, Corrêa BRS, et al. MicroRNA195 acts as an anti-proliferative miRNA in human melanoma cells by targeting Prohibitin 1. BMC Cancer. 2017;17(1):750.

151. Fan W, Yang H, Liu T, et al. Prohibitin 1 suppresses liver cancer tumorigenesis in mice and human hepatocellular and cholangiocarcinoma cells. Hepatology. 2017;65(4):1249-1266.

152. Siegel RL, Miller KD, Jemal A. Cancer statistics, 2015. CA Cancer J Clin. 2015;65(1):5-29.

153. Gong Y, Liu YR, Ji P, Hu X, Shao ZM. Impact of molecular subtypes on metastatic breast cancer patients: a SEER population-based study Sci Rep. 2017;7(1):45411.

154. Luo Q, Wei C, Li X, et al. MicroRNA-195-5p is a potential diagnostic and therapeutic target for breast cancer. Oncol Rep. 2014;31(3): 1096-1102.

155. Sauer K, Lehner CF. The role of cyclin E in the regulation of entry into S phase. Prog Cell Cycle Res. 1995;1:125-139.

156. Nakayama N, Nakayama K, Shamima Y, et al. Gene amplification CCNE1 is related to poor survival and potential therapeutic target in ovarian cancer. Cancer. 2010;116(11):2621-2634

157. Sinilnikova OM, McKay JD, Tavtigian SV, et al. Haplotype-based analysis of common variation in the acetyl-coA carboxylase alpha gene and breast cancer risk: a case-control study nested within the European Prospective Investigation into Cancer and Nutrition. Cancer Epidemiol Biomarkers Prev. 2007;16(3):409-415.

158. Lee JS, Sul JY, Park JB, et al. Fatty acid synthase inhibition by amentoflavone suppresses HER2/neu (erbB2) oncogene in SKBR3 human breast cancer cells. Phytother Res. 2013;27(5):713-720.

159. Bjarnadottir O, Romero Q, Bendahl PO, et al. Targeting HMG-CoA reductase with statins in a window-of-opportunity breast cancer trial. Breast Cancer Res Treat. 2013;138(2):499-508.

160. Lopes N, Sousa B, Martins D, et al. Alterations in Vitamin D signalling and metabolic pathways in breast cancer progression: a study of VDR, CYP27B1 and CYP24A1 expression in benign and malignant breast lesions. BMC Cancer. 2010;10(1):483.

161. Dunbar DR, Khaled H, Evans LC, et al. Transcriptional and physiological responses to chronic ACTH treatment by the mouse kidney. Physiol Genomics. 2010;40(3):158-166.

162. Singh R, Yadav V, Kumar S, Saini N. MicroRNA-195 inhibits proliferation, invasion and metastasis in breast cancer cells by targeting FASN, HMGCR, ACACA and CYP27B1. Sci Rep. 2015;5(1):17454

163. Wang Y, Zhang X, Zou C, et al. miR-195 inhibits tumor growth and angiogenesis through modulating IRS1 in breast cancer. Biomed Pharmacother. 2016;80:95-101.

OncoTargets and Therapy

\section{Publish your work in this journal}

OncoTargets and Therapy is an international, peer-reviewed, open access journal focusing on the pathological basis of all cancers, potential targets for therapy and treatment protocols employed to improve the management of cancer patients. The journal also focuses on the impact of management programs and new therapeutic agents and protocols on
164. Gibson SL, Ma Z, Shaw LM. Divergent roles for IRS-1 and IRS-2 in breast cancer metastasis. Cell Cycle. 2007;6(6):631-637.

165. Storm SM, Rapp UR. Oncogene activation: c-raf-1 gene mutations in experimental and naturally occurring tumors. Toxicol Lett. 1993;67(1-3): 201-210.

166. Yang G, Wu D, Zhu J, et al. Upregulation of miR-195 increases the sensitivity of breast cancer cells to Adriamycin treatment through inhibition of Raf-1. Oncol Rep. 2013;30(2):877-889.

167. Foulkes WD, Smith IE, Reis-Filho JS. Triple-Negative Breast Cancer. N Engl J Med Overseas Ed. 2010;363(20):1938-1948.

168. Furuya K, Sasaki A, Tsunoda Y, et al. Eribulin upregulates miR-195 expression and downregulates Wnt3a expression in non-basal-like type of triple-negative breast cancer cell MDA-MB-231. Hum Cell. 2016;29(2):76-82.

169. Cecene G, Ak S, Eskiler GG, et al. Circulating miR-195 as a Therapeutic Biomarker in Turkish Breast Cancer Patients. Asian Pac J Cancer Prev. 2016;17(9):4241-4246.

170. Nadeem F, Hanif M, Ahmed A, Jamal Q, Khan A. Clinicopathological features associated to MiRNA-195 expression in patients with breast cancer: Evidence of a potential biomarker. Pakistan J Med Sci. 2017; 33(5):1242-1247.

171. Zhao FL, Dou YC, Wang XF, et al. Serum microRNA-195 is downregulated in breast cancer: a potential marker for the diagnosis of breast cancer. Mol Biol Rep. 2014;41(9):5913-5922.

172. Allolio B, Fassnacht M. Clinical review: Adrenocortical carcinoma: clinical update. J Clin Endocrinol Metab. 2006;91(6):2027-2037.

173. Soon PS, Tacon LJ, Gill AJ, et al. miR-195 and miR-483-5p Identified as Predictors of Poor Prognosis in Adrenocortical Cancer. Clin Cancer Res. 2009;15(24):7684-7692.

174. Chabre O, Libé R, Assie G, et al. Serum miR-483-5p and miR-195 are predictive of recurrence risk in adrenocortical cancer patients. Endocr Relat Cancer. 2013;20(4):579-594.

175. Enewold L, Zhu K, Ron E, et al. Rising thyroid cancer incidence in the United States by demographic and tumor characteristics, 1980-2005. Cancer Epidemiol Biomark Prev. 2009;18(3):784-791.

176. Wang F, Jiang C, Sun Q, et al. miR-195 is a key regulator of Raf1 in thyroid cancer. Onco Targets Ther. 2015;8:3021-3028.

177. Yin Y, Hong S, Yu S, et al. MiR-195 Inhibits Tumor Growth and Metastasis in Papillary Thyroid Carcinoma Cell Lines by Targeting CCND1 and FGF2. Int J Endocrinol. 2017:6180425.

178. Rahib L, Smith BD, Aizenberg R, Rosenzweig AB, Fleshman JM, Matrisian LM. Projecting cancer incidence and deaths to 2030: the unexpected burden of thyroid, liver, and pancreas cancers in the United States. Cancer Res. 2014;74(11):2913-2921.

179. Zhou B, Sun C, Hu X, et al. MicroRNA-195 Suppresses the Progression of Pancreatic Cancer by Targeting DCLK1. Cell Physiol Biochem. 2017;44(5):1867-1881

180. Sureban SM, May R, Lightfoot SA, et al. DCAMKL-1 regulates epithelial-mesenchymal transition in human pancreatic cells through a miR-200a-dependent mechanism. Cancer Res. 2011;71(6):2328-2338.

181. Sureban SM, May R, Ramalingam S, et al. Selective blockade of DCAMKL-1 results in tumor growth arrest by a Let-7a MicroRNAdependent mechanism. Gastroenterology. 2009;137(2):649-659.

\section{Dovepress}

patient perspectives such as quality of life, adherence and satisfaction. The manuscript management system is completely online and includes a very quick and fair peer-review system, which is all easy to use. Visit http://www.dovepress.com/testimonials.php to read real quotes from published authors. 